FACTA UNIVERSITATIS

Series: Mechanical Engineering Vol. 16, $\mathrm{N}^{\mathrm{o}} 2,2018$, pp. 273 - 283

https://doi.org/10.22190/FUME171114026O

Original scientific paper

\title{
THE STUDY AND THE MECHANISM OF NITROGEN OXIDES' FORMATION IN COMBUSTION OF FOSSIL FUELS
}

\author{
UDC 691.141
}

\begin{abstract}
Bulbul Ongar' ${ }^{\text {, Iliya K. Iliev², Vlastimir Nikolić3 }}$, Aleksandar Milašinović ${ }^{4}$

${ }^{1}$ Almaty University of Power Engineering \& Telecommunications (AUPET), Faculty of heat energy, Almaty, Kazakhstan

${ }^{2}$ University of Ruse, Department of Thermotechnics, Hydraulics and Ecology, Ruse, Bulgaria

${ }^{3}$ University of Niš, Faculty of Mechanical Engineering, Serbia, Niš

${ }^{4}$ University of Banja Luka, Department of Vehicle and Engine, B\&H, Banja Luka

Abstract.The burning of all fossil fuels is accompanied by the production of large quantities of nitrogen oxides. Nitrogen oxide from coal combustion is formed from the molecular nitrogen in the air and the nitrogen contained in the fuel. In accordance with the mechanism of formation of nitric oxide from fuel, it is desirable to increase the concentration of coal dust in the flame. The thermal regime of combustion accelerates the release of volatiles, with flames spreading out and the coke residue contributes to the chemical reduction of $\mathrm{NO}_{x}$. In this work we consider the specific issues of the formation mechanism of $\mathrm{NO}_{x}$ fuel and ways to reduce their atmospheric emissions. Presented are results from the calculation of the influence of the following on the level of nitric oxides during coal combustion: temperature, oxygen concentration and time of release of fuel nitrogen. It has been established that the influence of nitric oxide fuel on the total nitric oxide emissions is more noticeable at low temperatures of the combustion process.
\end{abstract}

Key words: Coal gasification, Concentration of nitrogen oxides, Torch, Recombination, Burner

\footnotetext{
Received November 14, 2017 / Accepted July 10, 2018

Corresponding author: Ongar Bulbul

Almaty University of Power Engineering \& Telecommunications (AUPET), Faculty of Heat Energy,

Almaty 050060, Kazakhstan

E-mail: ongar_bulbul@mail.ru 


\section{INTRODUCTION}

Exhausted pollutants such as $\mathrm{NO}_{\mathrm{x}}, \mathrm{SO}_{\mathrm{x}}, \mathrm{CO}, \mathrm{CO}_{2}$, and unburned hydrocarbon particles, have been considered as one of the major sources of air pollution in urban regions, which seriously affect human health, environment, and economic development [1].

The trend towards more stringent regulations on emissions has been an important driving force in the search for more environmentally friendly engines [2].

Environmental pollution by toxic products from the combustion of organic fuels is one of the inevitable results of modern heat-power engineering. The main pollutants from that combustion are: coal - fly ash, oxides of sulphur and nitrogen. When burning fuel oil those are the sulphur and nitrogen oxides, whilst when burning natural gas, the polluters are nitrogen oxides.

Fly ashes and oxides of sulphur are formed in quantities, determined by the ash and sulfur contents. A decrease in their contents in the products of combustion is reached by cleaning combustion gases or through preliminary removal from fuel (through enrichment for decrease in the ash-content, removing of sulphur from fuel). In comparison to these pollutants, the level of formation of nitrogen oxides can be substantially regulated to a sufficient degree by means of flue/furnace gases. Direct experimental data about the role of preliminary heat treatment of fuel on the formation level of fuel oxides of nitrogen are known.

It is further known that at temperatures $700 \div 1200 \mathrm{~K}$ there are rather intensive recovery reactions of carbon dioxide and an oxide of nitrogen on carbon to carbon monoxide, and besides that the speed of the decomposition reaction of an oxide of nitrogen (at $\mathrm{T}>1200 \mathrm{~K}$ the reaction is sharply inhibited) is two orders higher than the speed of decomposition of carbon dioxide [3].

Research efforts continuously focus on modeling $\mathrm{NO}_{\mathrm{x}}$ formation/destruction reactions in pulverized coal combustion [4-8]. Nitric oxide (NO) is the most abundant $\mathrm{NO}_{\mathrm{x}}$ from coal combustion. The simulations often neglect fast NO (significant only in strong fuelrich flames), while considering fuel NO, typically accounting for 75-95\% of the total NO in coal combustors and thermal NO, becoming important for the flame temperatures above $1600-1800 \mathrm{~K}$.

An in-house developed 3D differential mathematical model of furnace processes, including the fuel- and thermal-NO formation/destruction reactions, validated against available measurements in the case-study boiler units [9-14], was used for the analysis. The comprehensive combustion code offers a balance between the sophistication of submodels describing individual processes and computational practicality.

The NO formation and depletion mechanisms were studied in dependence on twophase gas particle reactive turbulent flow and pulverized coal diffusion flame, accounting for extremely complex interactions between the influencing parameters. Impact of various operating conditions in the case-study furnace on the $\mathrm{NO}_{\mathrm{x}}$ emission and flame, like the fuel and the combustion air distribution over the burners and tiers, fuel-bound nitrogen content and grinding fineness of coal were investigated individually and in combination. Complex numerical experiments of this kind can help to optimize flow, combustion and heat transfer and improve the furnace exploitation regarding emission and efficiency. 


\section{DECREASE IN EMISSIONS OF NITROGEN OXIDES BY OPTIMIZATION OF FURNACE AERODYNAMICS}

Complex suppression of formation of nitrogen oxides demands a combinatorial approach involving thermochemistry, the aerodynamics of burning, hydromechanics and heat mass exchange.

Problems of thermophysics and power systems cause some incomparable interest and have a high value in practice. The relevance of this problem and the growing attention to it are related to the increase of energy use efficiency and to the solution of environmental problems, as well as to the increase in the amount of polluting substances released into the atmosphere, but also to the operation of existing power stations, in particular with the creation of new combustion chambers.

First of all, the power plants working with solid fuel are the main source of air pollution, water and the soil. This problem can be solved only on the basis of physical, mathematical and chemical modelling. In this regard numerical experiments become one of the most economical and convenient ways for the detailed analysis of the difficult physical and chemical phenomena occurring in the furnace camera. Use of modern computers allows to solve these problems for specific power stations (thermal power plant, state district power station, etc.) and for any power fuel [15].

When burning any type of organic fuel, a large amount of the nitrogen oxides promoting pollution of the atmospheric air is formed. Those include the following compounds: $\mathrm{N}_{2} \mathrm{O}$, $\mathrm{NO}, \mathrm{N}_{2} \mathrm{O}_{3}, \mathrm{NO}_{2}, \mathrm{~N}_{2} \mathrm{O}_{4}$ and $\mathrm{N}_{2} \mathrm{O}_{5}$. In practice only the oxide $\mathrm{NO}$ and the dioxide $\mathrm{NO}_{2}$ of nitrogen matter from the point of view of ecology, their sum in terms of dioxide of nitrogen designate $\mathrm{NO}_{\mathrm{x}}$. As per the obtained data, the degree to which nitrogen oxides determine the toxicity of the flue gases when burning coal and fuel oil is 40-50\%, rising to $90-95 \%$ when burning natural gas. Furthermore, NO accounts for about $95-99 \%$ of the nitrogen oxides $\mathrm{NO}_{\mathrm{x}}$ formed in the boiler, whereas $40 \div 80 \%$ of the nitric oxide, contained in the flue gases is further oxidised to $\mathrm{NO}_{2}$ in the atmosphere.

Nitrogen oxides when burning coal can be formed from molecular nitrogen in the air and nitrogen-containing components of the fuel. There are three types of mechanisms allowing for their formation: thermal, fuel and fast. During the combustion of natural gas thermal and fast $\mathrm{NO}_{\mathrm{x}}$, are formed, whereas during the combustion of heavy fuel oil or coal - thermal and fuel $\mathrm{NO}_{\mathrm{x}}$. Formation of thermal nitrogen oxides occurs on the basis of the Zeldovich mechanism. These reactions are characterized by a high activation energy and proceed at temperatures over $1800 \mathrm{~K}$ [3]. Two balancing reactions offered by Zeldovich are given below taking into account the chain mechanism of the formation $\mathrm{NO}$ which is put forward by:

$$
\begin{aligned}
& O+N_{2 \underset{K_{3}}{\stackrel{K_{1}}{\rightleftarrows}}}^{\stackrel{2}{\longrightarrow}} \mathrm{O}+N-197 \mathrm{~kJ}
\end{aligned}
$$

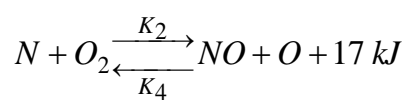

where $O$ - oxygen, $\% ; \mathrm{N}_{2}-$ molecular nitrogen, $\% ; N O$ - concentration of an oxide of nitrogen, $\% ; N$ - nitrogen, $\% . K_{1}$ and $K_{2}$ - speed constants of the direct reaction in Eqs. (1) and (2), $K_{3}$ and $K_{4}$ speed constants of the reverse reaction respectively. The differential equation for $N O$ formation due to excess concentration of oxygen is as follows: 


$$
\frac{d N O}{d \tau}=\frac{5 \cdot 10^{11}}{\sqrt{O_{2}}} \cdot e^{-\frac{86000}{R T}} \cdot\left[O_{2} \cdot N_{2} \cdot \frac{64}{3} \cdot e^{-\frac{43000}{R T}}-(N O)^{2}\right]
$$

where $\tau$-the time, $\mathrm{s} ; R$ - the universal gas constant, $R=8.314 \mathrm{~J} /(\mathrm{mol} \cdot \mathrm{K}) ; T$ - the absolute temperature, $\mathrm{K}$.

Settlement calculations are provided in [16] during the analysis of the NOx concentration in the flames of a swirl burner and a straight flow one. The amount of nitrogen oxides formed when using swirl burners depends on the intensity of the swirl of a stream and can be estimated by means of the following dependence:

$$
N O_{X} \approx N O_{X} \cdot(1+n)^{0.8}
$$

where $N O_{x}$ - the concentration in a swirl burner, $\mathrm{g} / \mathrm{Nm}^{3}$ and $n$ - the amount of stream swirl in the given burner, $\mathrm{g} / \mathrm{Nm}^{3}$.

It is known that NO formation during the combustion process occurs at the end of the torch, in the stage of burning out of volatiles.

According to the approximate mechanism of formation of NO fuel, in the beginning fuel nitrogen passes in intermediate radical connections, after which it is partially oxidized to NO.

Mass and spectroscopic analysis showed presence of active radicals of $\mathrm{CN}, \mathrm{HCN}, \mathrm{NH}$, $\mathrm{NH}_{2}$ and $\mathrm{OH}$ at an initial stage of burning. Furthermore, according to [17] there are the following reactions:

$$
\begin{gathered}
\mathrm{HCN}+\mathrm{H}_{2} \mathrm{O} \rightarrow \mathrm{NH}_{3}+\mathrm{CO} \\
\mathrm{NH}_{3}+\mathrm{O}_{2} \rightarrow \mathrm{NO}+\mathrm{H}_{2} \mathrm{O}+1 / 2 \mathrm{H}_{2}
\end{gathered}
$$

It is established that the level of conversion (transition) of fuel nitrogen to nitrogen oxides significantly depends on the content of nitrogen in the initial fuel. At small contents of fuel nitrogen (less than one percent) it is almost entirely converted to $\mathrm{NO}_{\mathrm{x}}$. However, at a level of nitrogen content in the fuel $1 \div 1.3 \%$, merely $16 \div 25 \%$ is converted into $\mathrm{NO}_{\mathrm{x}}$. It is also accepted that the formation level of nitrogen oxides significantly depends on the concentration of oxygen in a torch's zone of ignition and in this regard it depends on the excess of air in said torches.

The maximum quantity of fuel nitrogen oxides is formed at excess air ratio $\alpha=0.85 \div 0.9$. Compared to thermal nitrogen oxides, the dependence of the formation level of nitrogen oxides on temperature has a more difficult character. In particular, in the temperature zone of $1000 \div 1400 \mathrm{~K}$ an almost exponential dependence of formation level of the fuel takes place. At further temperature increase, (higher than $1400 \mathrm{~K}$ ) this dependence gains a linear character [3]. Fast fuel nitrogen oxides (typical for hydrocarbonic fuels) are formed in the root part of a torch. That reaction is characterized by a very high speed (considerably bigger than formation of thermal NO). 
Fenimore [18] made the assumption that the formation of fast nitrogen oxides is promoted by binding of molecules of nitrogen by the active radicals mentioned earlier, for example $\mathrm{CH}$ and $\mathrm{C}_{2}$ [19-21] Binding reactions of $\mathrm{N}_{2}$ can look as follows:

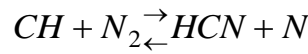

$$
\begin{aligned}
& 2 C+N_{2 \leftarrow} \rightarrow C N \\
& \mathrm{CH}_{2}+\mathrm{N}_{2 \longleftarrow} \underset{\leftarrow}{\rightarrow} \mathrm{C}+\mathrm{NH} \\
& \mathrm{N}+\mathrm{OH}_{\leftarrow}^{\rightarrow} \mathrm{H}+\mathrm{NO}
\end{aligned}
$$

The existence of a large concentration of HCN near a zone of burning experimentally confirms the possibility of NO formation according to the specified scheme. The share of fast $\mathrm{NO}$ of the total formed $\mathrm{NO}_{\mathrm{x}}$ is usually relatively small and makes up about $10 \div 15 \%$.

In it is noted that the temperature of the most intensive formation of fast nitrogen oxides ranges between $1200 \div 1600 \mathrm{~K}$. The maximum level of formation of fast oxides is observed at excess air ratio $\alpha=0.65 \div 0.8$ which are values slightly less than those of excess of air of the fuel nitrogen oxides specified by our consideration. It is remarkable that at $\alpha<0.6 \div 0.7$ there is some decrease in the formation level of fast nitrogen oxides (Fig. 1). More intensive formation of carbon monoxide and its partial restoration to molecular nitrogen can perhaps be the cause of this decrease.

From Fig. 1 we observe that the higher the temperature of the process, the faster the exit of atomic nitrogen and its recombination, the former of which happens in less than $0.04 \mathrm{~s}$.



Fig. 1 A recombination of $\mathrm{N}$ in $\mathrm{N}_{2}$ depending on the temperature level of process at various values of concentration of oxygen $1 \%(1), 2 \%(2), 3 \%$ (3), $4 \%$ (4) and $5 \%(5)$ of oxygen 
The recombination of atomic nitrogen in molecular nitrogen occurs as depicted in Fig. 2 , for a very short time, less than $0.04 \mathrm{~s}$ at a temperature $\mathrm{T}=800 \div 1600 \mathrm{~K}$; at a content of oxygen $\mathrm{O}_{2}$ no more than $3 \%$ in the combustion gases (recirculation to a torch root).

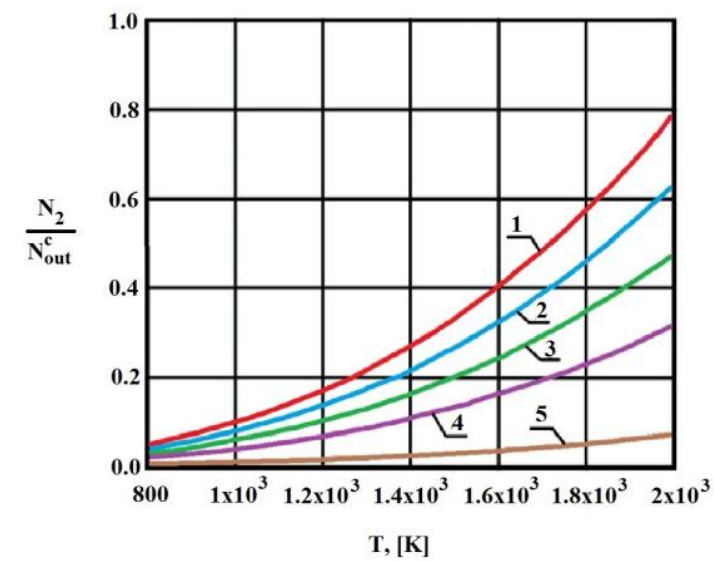

Fig. 2 A recombination of $\mathrm{N}$ in $\mathrm{N}_{2}$ depending on time at various $\mathrm{O}_{2}$ : $1 \%(1), 2 \%(2), 3 \%(3), 4 \%(4), 5 \%(5)$ and $6 \%(6)$

Thus, a decrease in the emissions of nitrogen oxides by influencing furnace aerodynamics and conditions of burning can be obtained by the following actions [22]:

- burning of fuels at small excess of air

or

- recirculation of the products of combustion in the furnace camera (the greatest effect on decrease in an exit of $\mathrm{NO}_{\mathrm{x}}$ is reached at recirculation introduction directly to the hot air before the torches).

However, these methods have limitations, namely:

- considerable complication of torch ignition at decrease in the oxygen content in the burning zone;

- temperature increase of overheated steam in connection with a tightening of ignition and burning out of fuels;

- some decrease in the completeness of the burning out of fuel (increase of heat losses due to unburnt or the emergence of unburnt chemicals).

These actions are generally directed at the decrease in the maximum temperatures in a zone of active burning, and at the reduction of oxygen concentration, and furthermore at the creation of a recovery environment for the NO formed. Other possibilities of achieving a decrease in the formation level could be:

- phasic (step) burning of organic fuels (reduction of oxygen concentration and temperature decrease in the ignition zone)

- application furnace burner devices providing a realization of the noted conditions for the decrease in formation level of nitrogen oxides.

It is specified that a decrease in the $\mathrm{NO}_{\mathrm{x}}$ quantity of $40 \div 50 \%$ when burning gas and of $25 \div 40 \%$ when burning fuel oil has been successful. However, burning of fuels with small excess of air can lead to the formation of soot and a strong carcinogenic compound - 
benzo[a]pyrene. The situation can be exacerbated considerably given an unsatisfactory state of the furnace burner devices and their imperfections.

Use of straight-flow burners (as a rule in tangential fire chambers) in combination with a certain aerodynamic scheme of burning allows for a phasic supply of an oxidizer in the horizontal direction and step-wise burning to be organised. In various schemes the question of introduction of gases of recirculation to the fuel ignition zone can be considered.

Thus, in such a scheme it is possible to implement all three mechanisms of influence on the level of formation of nitrogen oxides, which may contribute to the high effectiveness of straight-flow burners and tangential furnaces.

\section{THE DETERMINATION OF THE LEVEL OF FORMATION OF NITROGEN OXIDES BY VARYING THE FUEL CONCENTRATION IN THE BURNER}

When complex burning of nitrogen oxide pollutants takes place, it is important to optimise the burning processes first and foremost by undertaking actions related to the burner's mode of operation. According to the mechanism of formation of fuel nitrogen oxides, an increase of concentration of coal dust in the aero mix is necessary. The latter, respectively the thermal mode of burning, promotes an exit of volatiles and their ignition in the conditions of relative oxygen insufficiency. In this regard the application of supply of coal dust together with the overall concentration considerably exceeding the traditional ratio of air and coal dust can be one of the possible mechanisms to reach a decrease in the formation level of nitrogen oxides.

Such modes can analytically be predetermined and embodied in the designs of burner arrangements and it is easy for them be established during operation of regular installations, taking into account the concentration characteristics of the given coal dust.

This idea was realized on the P-57-3M No. 8 EHEPS-1 package boiler under the possible conditions of operation of the burner arrangements [23]. Tests were carried out at electric loading of the block with a power of $450 \mathrm{~mW}$, a coefficient of excess of air behind a transitional zone 1.15 , respectively behind an air heater 1.33 , and temperature of feed water $\mathrm{T}=483 \mathrm{~K}$ in an operating mode of the package boiler without HDC.

Fuel consumption equalled $83.33 \mathrm{~kg} / \mathrm{s}$ at the following parameters of the package boiler. $\mathrm{Q}_{\mathrm{i}}^{\mathrm{r}}=15.56 \mathrm{MJ} / \mathrm{kg}, \mathrm{A}^{\mathrm{r}}=41 \%, \mathrm{~W}^{\mathrm{r}}=7 \%$. The consumption of primary air in the three mills was on average $0.393 \mathrm{~nm}^{3} / \mathrm{s}$, as for the others it was $0.16 \mathrm{~nm}^{3} / \mathrm{s}$. The content of combustibles in slag was $7.5 \%$, and in the flue gases $4.3 \%$. Heat losses with exhausted flue gases, with mechanically unburnt fuel, and due to radiation along with the physical heat of slag equal respectively $4.09 \% ; 3.88 \% ; 0.29 \%$. Gross hopper efficiency was $91.74 \%$ and $92.03 \%$ before and after tests respectively, and expenses on own needs increased by $0.12 \%$. Sampling was carried out in the splitting of the flue at the level of the water economizer. The content of nitrogen oxides was determined by the device "Eudiometer-1". The torch temperature was estimated by means of a pyrometer.

Expenses of air and other parameters were fixed on panel board devices. In processing thermos-aerodynamic and the chromatographic of data, representatives of KAZNIIE and service TSNITO EGRES-1 took part in the preparation of tests and the measurements of parameters. 
In normal operation of the boiler, the average value of the concentration of nitrogen oxides at the measuring point was $\mathrm{NO}_{\mathrm{X}}=0.864 \mathrm{~g} / \mathrm{Nm}^{3}$ with an average value of flame temperature at the outlet of the furnace of $\mathrm{T}=1618 \mathrm{~K}$.

As a result of the redistribution of air streams by way of the translation of primary air consumption to secondary air, a reduction of the content of nitrogen oxides in combustion products of $28 \%$ on average is reached, i.e. decreased to $0.62 \mathrm{~g} / \mathrm{Nm}^{3}$, at an average value of temperature of the torch at the exit from the fire chamber of $\mathrm{T}=1598 \mathrm{~K}$.

Thus, the results presented from the carried out test on the method of suppressing the formation of nitrogen oxides using measures related to the operational regime showed that a decrease in the formation level of nitrogen oxides is possible. Regime actions represent part of the complex suppression of formation of nitrogen oxides, so we outlined a number of essential actions to be undertaken to aid in this aforementioned reduction on a global scale [23].

The method of preliminary gasification of fuel is one of the possible ways of global suppression of formation of nitrogen oxides.

On the other hand, at the initial phase of ignition of the torch to a certain degree, is the process of coal gasification. In particular, it is known that at temperatures 700-1200 K quite intense redox reactions take place. Thus, the speed of reaction of the formed nitrogen oxide decomposition is two orders higher than the speed of decomposition of carbon dioxide. The result is expected to reduce the concentration of nitrogen oxides in the combustion chamber of the Ekibastuz Condensing Thermal Power Plant by means of fire-technical methods to a level of less than $0.2 \mathrm{~g} / \mathrm{Nm}^{3}$, i.e. by decreasing the concentration of nitrogen oxides this should take place 4-5 times.

The $\mathrm{NO}_{\mathrm{x}}$ emissions on level are reduced for the emulsion fuels compared to neat diesel: the higher the water content - the smaller the $\mathrm{NO}_{\mathrm{x}}$ emission. As the engine load is increasing, a slighter increase of $\mathrm{NO}_{\mathrm{x}}$ emission, at engine speeds of 1100 and $2100 \mathrm{rpm}$, can be observed. At engine speed of $1700 \mathrm{rpm}$ and engine load of 300 and $450 \mathrm{Nm}$, the highest $\mathrm{NO}_{\mathrm{x}}$ emission reduction was reached. The most notable reduction was of $67 \%$ for the emulsion of $10 \%$ water ratio and of $71 \%$ for the emulsion of $25 \%$ water ratio, at engine torque of $300 \mathrm{Nm}$. This can be explained by higher carbon oxidation due to water droplet micro-explosion which provides a better mixing of fuel and in-cylinder air. This assumption is supported by the reduced levels of $\mathrm{O}_{2}$.

\section{RESULTS AND DISCUSSION}

According to Fig. 2, the possible recombination of atomic nitrogen in molecular nitrogen occurs in a very short time, less than 0.04 seconds, in the wide range of change in the concentration of oxygen. The purpose of the experimental confirmation of this position is marked with a vertical tubular furnace upgraded as follows (Fig. 3).

Tube 7 made from stainless steel with a diameter of $10 \mathrm{~mm}$ was installed in the furnace for air supply from below.

Preheated argon from electric furnace 6 was introduced in mixer 5 of the system with central cross streams. Dust from Ekibastuz coal was brought into the system through feeder 4 , located above the mixer. The time of crossing of the air stream with the heated up by the argon in the mixer coal dust was regulated by accounting for the velocity of the 
gas-mix by the vertical displacement of tube 7 along the vertical combustion chamber. Air in the form of transverse jets was supplied into the stream of gas-mix (Fig. 3).

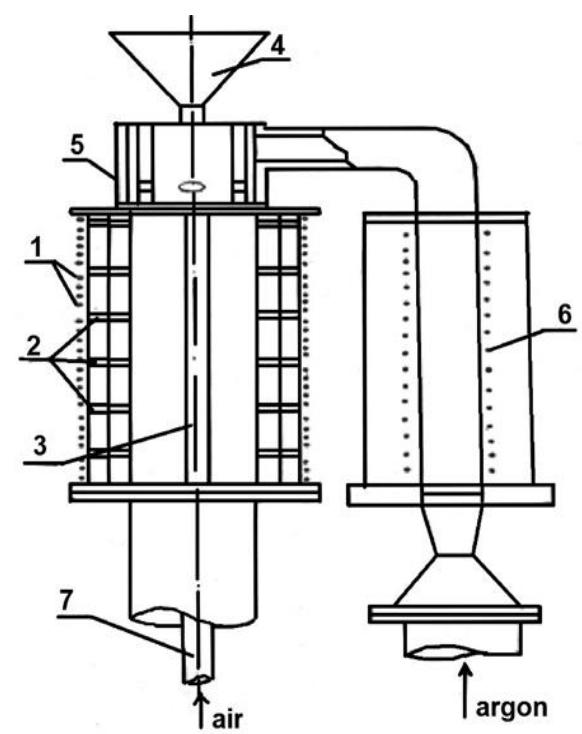

Fig. 3 Schema of pilot unit: 1-Furnace electric heater; 2-holes for thermocouples;

3-peephole; 4-burner pulverized feeder; 5- mixing machine; 6-electric heating unit of a gas; 7-tube for air supply

Owing to the vertical supply of the stream during the experiment, the coal dust instantly mixes with the system of vertical argon streams, and consequentially the same momentary crossing of streams occurs between the gas mixture and the air. The concentration of oxygen in the system was regulated by the ratio between the air consumption and the argon gas. Height of the furnace and the accepted flowmeters allowed setting time of shift of phases and temperature in the furnace with an accuracy of $20 \%$.

Experiments were made with dust of Ekibastuz (Kazakhstan) coal. The dust consumption in all experiments was kept constant at made $0.042 \mathrm{~g} / \mathrm{s}$. The excess air ratio was $\alpha=1.2$, and the temperature in the furnace changed from $\mathrm{T}=773 \mathrm{~K}$ to $\mathrm{T}=973 \mathrm{~K}$. The oxygen concentration in the furnace was $11 \%$. It was determined by using the chromatograph LHM-8MD. A determination of the concentration of nitrogen oxide was performed using, as noted, the device of the "Eudiometer-1". The technique of carrying out gas analyses is described in [23].

A mathematical model of solidification works integrated with a genetic search algorithm and a knowledge base of operational parameters is presented. Surekha et al. [24] presented multi-objective optimization of green sand mould system using evolutionary algorithms, such as genetic algorithm (GA) and particle swarm optimization (PSO). Dučić et al. [25] presented optimization of chemical composition in the manufacturing process of flotation balls based on intelligent soft sensing. The implementation of modern CAD/CAM software systems is frequent in the research projects of the process, as well as the combination of modern CAD/CAM software systems and methods of metaheuristic optimization. 


\section{CONCLUSIONS}

At torch burning in furnace chambers of the boilers, at the initial stage of the burning process (during the release of the volatile components) the volatiles emit a part of the compound as water vapour and nitrogen-containing gases. The latter are oxidized with the formation of nitrogen oxides, the level of which depends on the content of oxygen and the temperatures in the fuel ignition zone. The fuel nitrogen which remained in coke at the secondary combustion is also partially converted to oxidized nitrogen, but its share in comparison with the emissions of nitrogen fuel oxides from the gas phase is insignificant.

The maximum release of fuel $\mathrm{NO}_{\mathrm{x}}$ is observed at the end side of the torch, at the stage of ignition and burning of volatiles, at temperatures of $\mathrm{T}_{\max }=1200 \div 1800 \mathrm{~K}$.

The influence of fuel nitrogen oxides on the general emissions of nitrogen oxides is more significant at low temperatures of the burning process.

Acknowledgement: We express special gratitude to Doctor of Technical Sciences, Professor B.K. Aliyarov, for his encouraging recommendations on research in the field of formation of nitrogen oxides in the combustion of partially gasified coal. The study was supported by the Almaty University of Energy and Communications.

\section{REFERENCES}

1. Fan, X., Hu, W., Yang, J., 2008, Micro-emulsified diesel oil. Petroleum Science and Technology, 26, pp. 2125-2136.

2. Armas, O., Ballesteros, R, Martos, F.J., 2005, Characterization of light Diesel engine pollutant emissions using water-emulsified fuel, Fuel, 84, pp. 1011-1018.

3. Kotler, V.R., 1987, Reduction of emissions of nitrogen oxides by boilers of thermal power plants during the burning of organic fuel. Ser. "Boiler installations and water treatment", Itogi Nauki i Tekhniki.-M .: VINITI, p. 92.

4. Shi, L., Zhongguang, F., Xuenong, D., Changye, C., Yazhou, S., Binghan, L., Ruixin, W., 2016, Influence of Combustion System Retrofit on NOx Formation Characteristics in a 300 MW Tangentially Fired Furnace, Appl. Therm. Eng., Supp C, 98, pp. 766-777.

5. Askarova, A.S., Messerle, V.E., Ustimenko, A.B., Bolegenova, S.A., Bolegenova, S.A., Maximov, V.Yu., Yergaliev, A.B., 2016, Reduction of Noxious Substance Emissions at the Pulverized Fuel Combustion in the Combustor of the BKZ-160 Boiler of the Almaty Heat Electropower Station Using the "Overfire Air" Technology, Thermophys. Aeromech., 23(2), pp. 125-134.

6. Belosevic, S., Tomanovic, I.D., Crnomarkovic, N., Milicevic, A., Tucakovic, D., 2016, Numerical Study of Pulverized Coal-Fired Utility Boiler over a Wide Range of Operating Conditions for In-Furnace SO2/NOx Reduction, Appl. Therm. Eng., 94(1), pp. 657-669.

7. Constenla, I., Ferrín, J.L, Saavedra, L., 2013, Numerical Study of a 350 MWe Tangentially Fired Pulverized Coal Furnace of the As Pontes Power Plant, Fuel Process. Technol., 116, pp. 189-200.

8. Wang, Z., Sun, S., Qian, L., Meng, S., Tan, Y., 2013, Numerical Study on the Stereo-Staged Combustion Properties of a 600 MWe Tangentially Fired Boiler, Eds. H. Qi, B. Zhao, in: Cleaner Combustion and Sustainable World, Springer-Verlag Berlin Heidelberg and Tsinghua University Press, pp. 1141-1152.

9. Belosevic, S., Beljanski, V., Tomanovic, I.D., 2012, Numerical Analysis of NOx Control by Combustion Modifications in Pulverized Coal Utility Boiler, Energ. Fuel., 26(1), pp. 425-442.

10. Zhou, H., Mo, G., Si, D., Cen, K., 2011, Numerical Simulation of the NOx Emissions in a 1000 MW Tangentially Fired Pulver-ized-Coal Boiler: Influence of the Multi-Group Arrangement of the Separated over Fire Air, Energ. Fuel., 25(5), pp. 2004-2012.

11. Liu, H., Liu, Y., Yi, G., Nie, L., Che, D., 2013, Effects of Air Staging Conditions on the Combustion and NOx Emission Characteristics in a 600 MW Wall Fired Utility Boiler Using Lean Coal, Energ. Fuel., 27(10), pp. 5831-5840.

12. Vascellary, M., Cau, G., 2012, Influence of Turbulence-Chemical Interaction on CFD Pulverized Coal MILD Combustion Modeli., Fuel, 101, pp. 90-101. 
13. McAdams, J.D., Reed, S.D., Co, J.Z., Itse, D.C., 2001, Minimize NOx Emissions Cost-Effectively, Hydrocarb. Process., 80(6), pp. 51-58

14. Belosevic, S., Sijercic, M., Crnomarkovic, N., Stankovic, B., 2009, Numerical Prediction of Pulverized Coal Flame in Utility Boiler Furnaces, Energ. Fuel., 2311, pp. 5401-5412.

15. Askarova, A.S., Bolegenova, S., Bekmukhamet, A., Maximov, V., 2012, 3D modelling of heat and mass transfer in industrial boilers of Kazakhstan power plant, $2^{\text {nd }}$ International Conference on Mechanical, Production and Automobile Engineering (ICMPAE-'2012), Singapore, April, pp. 217-220.

16. Sigal, I.Y., 1989, Ways of reducing nitrogen oxide emissions in thermal power plants, Teploenergetika, 3, pp. 5-8.

17. Kotler, V.R., 1987, Nitrogen oxides in boiler flue gases, Energoatomizdat, p.144.

18. Fenimore, C.P., 1971, Formation of nitric oxide in premixed hydrocarbon flames, Thirteenth symposium on combustion - The Combustion Institute, pp. 374-384.

19. Sigal, I.Y., 1988, Air protection when burning fuel, Nedra, p. 312

20. Roslyakov, P.V., Zakirov, I.A., 2001, Non-stechiometric burning of natural gas and heavy fuel oil at thermal power plants, Izdatel'stvo MEI, p. 144

21. Sigal, I.Y., 1983, Development and tasks in the research on the development of nitrogen oxide formation conditons in furnace processes, Teploenergetika, 9, pp. 5-108.

22. Putilov, V.Y., 2007, Modern nature protection technologies in power industry, The information collection, MEI publishing house, $388 \mathrm{p}$.

23. Temirbaev, D.Zh., 1992, The study of thermochemistry of oxides of nitrogen combustion of Ekibastuz high concentration coal, Final report on HDT №17/91. - №GR 01910009373. - Almaty AEU, 48 p.

24. Surekha, B., Kaushik, K.L., Panduy, K.A., Vundavilli, R.P., Parappagoudar, B.M., 2012, Multi-objective optimization of green sand mould system using evolutionary algorithms, The International Journal of Advanced Manufacturing Technology, 58(1), pp. 9-17.

25. Dučić, N., Ćojbašić, T., Slavković, R., Jordović, B., Purenović, J., 2016, Optimization of chemical composition in the manufacturing process of flotation balls based on intelligent soft sensing, Hemijska industrija, 70(6), pp. 603-614. 